\title{
Policy Processes as Complex Systems: The case of Mesoamerican Sustainable Development Initiative
}

\author{
Patricia E. Almaguer-Kalixto* \\ Grupo de Estudios Sociales y Económicos del Tercer Sector, \\ Universidad de Zaragoza, España \\ endev.research@gmail.com
}

José A. Amozurrutia

Centro de Investigación Interdisciplinarias en Ciencias y Humanidades, Universidad Nacional Autónoma de México, México;

j.amoz@yahoo.com

\section{Chaime Marcuello Servós}

Grupo de Estudios Sociales y Económicos del Tercer Sector, Universidad de Zaragoza, España

chaime@unizar.es

\begin{abstract}
This paper presents a research methodology for analyzing policy processes that are defined at the global level but implemented locally. The interrelations between these two levels pose great conceptual challenges in explaining the changes, transformations and continuations occurring in this complex process based on empirical information. Understanding the policy process as a complex system, this paper proposes analyzing macro, meso and micro levels as subsystems of the total process, identifying the interrelations between policy action, actors and discourses. The paper takes the example of the Mesoamerican Sustainable Development Initiative (MSDI) of the Puebla Panama Plan (PPP), a regional integration plan for a new 'Mesoamerica' that originally included the seven Central American countries and the southern states of Mexico.
\end{abstract}

Keywords: policy process analysis, complex systems, multi-level analysis, discourse, regional integration. 


\section{Introduction}

What research methodology can be used to analyze policy processes that are defined at the global level but implemented locally? Increasingly, policy processes seem to be influenced by multiple forces, and heterogeneous actors interacting from scattered settings, making it difficult to understand specific policy actions in relation to their extended decision-making processes. In addition, while policy communities are globalised by international organizations, enabling their intervention in domestic policies, we are also witnessing the increasing sensitivity of local reaction to global decision processes. By approaching the policy process as a complex and dynamic system, this paper proposes analyzing the macro, meso and micro levels as subsystems of the total process to identify the interrelations between policy action, actors and discourses.

Analytical perspectives have moved from linear models to explanations that increasingly address the complexity of the policy process. This change of perspective implies that when defining public policy, attention is given to the elements and conditions that enable specific interactions between social forces between different agents and at different levels (Sutton, 1999).

The turn in policy inquiry promoted by Fischer $(1998,2006)$ and Hajer and Wagenaar (2003), has conceptually strengthened deliberative analysis but also raised new methodological challenges in both, assessments and evaluations of implementation policies (Andersson \& Kalman 2011). Holmes and Scoones (2000) refer to deliberation as discussion arguing for and against a proposal or decision to seek political influence in the political process. For Blaikie and Muldavin (2004), this deliberative arena are the 'border of negotiation' where arguments are presented and contested within a power structure in which actors become claim-makers depending on their symbolic power, position and interests. By considering deliberative practices (sets of rules) as formal and/or informal, established among actors and employing strategies with the aim of reaching agreement through argumentation, the policy process analysis becomes more focused on dialogue with citizens, experts, media and other agents previously given less analytical attention (Dryzek, 1987) (Fischer, 2006).

Deliberative analysis suggests following the form and content of communicative interactions between actors. This requires addressing not only the discourse, in which perceptions, values and definitions can be traced, but also the actors' interactions within the policy process. Empirical analysis of deliberative settings is necessary because although deliberative policy represents an important advance in theory and practice, good deliberation is not a de facto situation. Institutions of power, social relationships and cultural expectations need to be taken into consideration in analysis and practice as well as how individuals relate to patterns of governance. Nonetheless, we consider, the very essence and quality of the deliberation processes (Baber, 2004), as well as issues of 
constraint, exclusion and asymmetry in the deliberative setting need to be addressed to make the research relevant, because 'despite intensive development efforts in institutionalizing participatory processes, non-deliberative decision processes continue both at the local community and national policy levels due to the control of decision spheres by people who enjoy greater symbolic privileges in the deliberative settings' (Cameron \& Ojha, 2007, p. 68). While recognizing the complex nature of policy, we need new tools and strategies to address its analysis.

But where does one start from, and how can the construction process be explained? To investigate a policy process it seems necessary to start from different points simultaneously, as it might be necessary to collect information scattered across organizations and actors that may even be in distant locations, whether the political process is a European framework, a Latin American regional development plan or a program for political cooperation in a specific region of a large country. This paper advocates an integrated approach to the analysis of policy as a system and as a complex process. It is not its objective to develop a theoretical argument about system dynamics and complex systems (García, 2006), but we consider it necessary to explain our points of reference related to this conceptual framework as this contributes to explaining change, transformation and continuation in policy-making processes.

System dynamics could be focused as particular field of Sociocybernetics. This is broadly defined as applications within the social sciences of first- and second-order cybernetics, general systems theory and the various combinations and variations of these that can be subsumed under the term 'the emerging science of complexity' (Geyer, 1995) (Scott, 2003) (Hornung, 2006). It centers its attention on social problems from a systemic perspective taking into consideration environmental or contextual conditions. We consider this key in policy process analysis, as it enhances the analysis of the processes that cause change in social systems towards greater levels of complexity, moving from top-down models based in a homeostatic equilibrium to explaining morphogenesis as a result of interpenetrating bottom-up processes (Geyer, 1995).

Policy process is a concatenation of interrelated actions performed by different agents in a period of time. We have asserted, however, that if actors' interactions and discourses are taken into account this is not a linear concatenation of actions but a complex web of codes, functions and structures that shape the process. This is consistent with deliberative policy analysis, where 'words and language, especially when combined with power, are recognised themselves to be a form of action, and thus important data for political and policy analysis' (Fischer, 2003, p. viii). Following the deliberative approach, we propose a unit of analysis that focuses on the relations between policy action, actors' interactions and discourse production, taking into consideration the fact that the intersection between these three domains: a) is not linear but interdefined, and $b$ ) as part of the feedback process, it produces a new or modified input that feeds again in the process. For example, actors, institutions and stakeholders 
engage in policy action such as meetings, deliberations or even protests in order to influence policy outcomes. In such processes they all deliberately produce discourses (i.e. text, speeches, pamphlets) to influence the policy process, but also in relation to the policy action in which they and others participate. However, this circularity also a feedback as policy actions have an impact and thus impact in actors and discourses. Thus the interrelations among these three elements are key to understanding the policy process systemically, as Figure 1, below, illustrates:

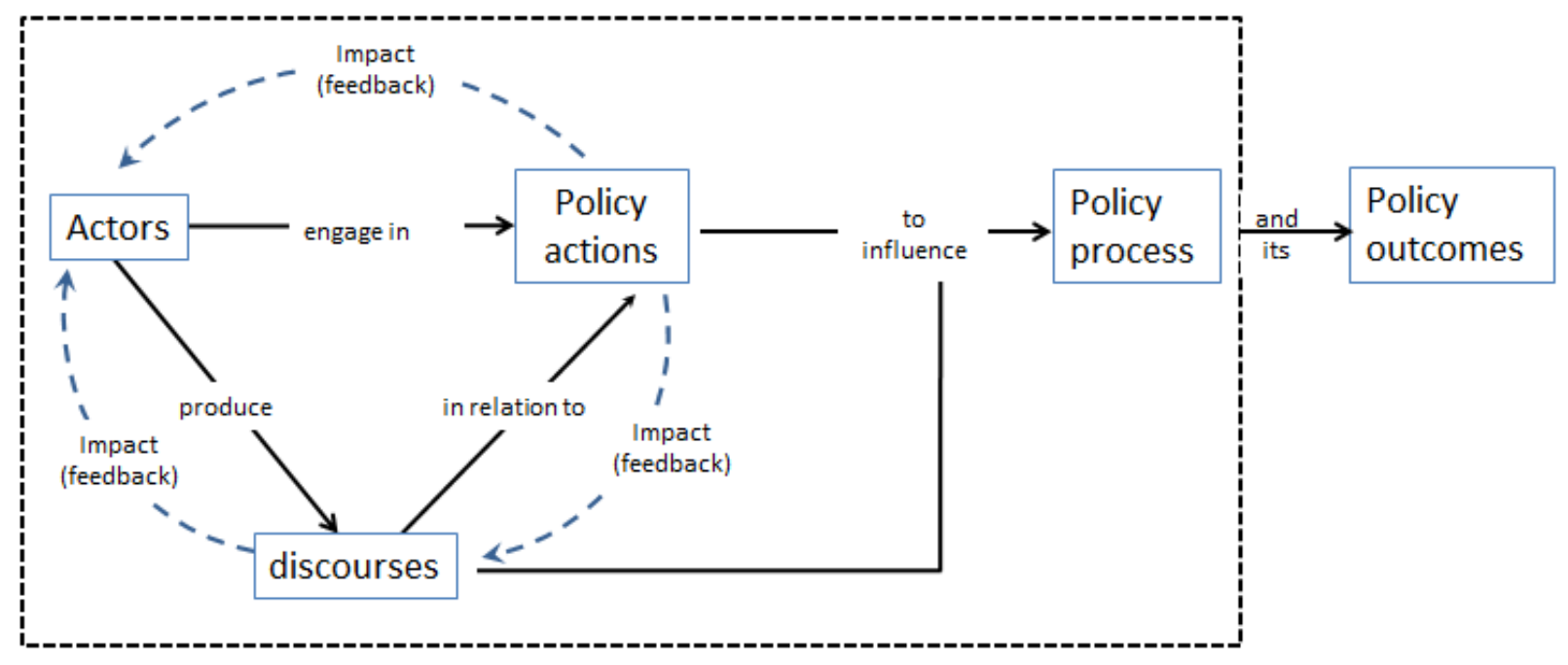

Figure 1: Policy actions, actors and discourses within the policy process

Due to its complexity, policy process analysis needs to approach its object of study in an integrated way as it involves great challenges in the logistics of the fieldwork, the data collection, the systematization and the analysis. The case-study approach is recommended as it can incorporate a variety of research techniques and sources of evidence (Yin, 1993) (Yin, 2003). This is particularly attractive for researchers interested in the 'analysis of multiple levels or components' (Vaus, 2001, p.220) and explanatory research which is partly why it is a key approach in policy studies and political processes in various fields (Stake, 1995).

A single or multiple case study can be used, depending on the research question, the objective and the researcher's time and budget constraints. If resources are scarce, a single case studied in depth can provide a good contribution of knowledge about the specific topic chosen. As argued by Macpherson, Brooker and Ainsworth (2000) through case study research it is possible of creating thick descriptions and rich understandings of social contexts that have relevance and resonance across social sites. 
This can be useful for creating insights for public policy makers as well as for social actors engaged in the policy process. In the following sections we focus on the methodological steps towards addressing this approach, suggesting some steps with which to analyze the discursive dimension and the actors' performance within the policy process.

\section{The discursive dimension of the policy process}

Taking Hajer's definition of discourse as 'a specific ensemble of ideas, concepts and categorizations that are produced, reproduced and transformed to give meaning to physical and social relations' (Hajer, 1995, p.44); we consider discourse analysis a useful tool for policy process analysis. For Fischer (2003), this approach offers the opportunity to access the social meaning of the dynamics under research and to gain an understanding of the institutional practices of a society. It can also help to examine the policy process through the frame of the policy problems to be tackled (Janks, 1997), the paths of intervention, bias in inclusion and exclusion practices (Fischer \& Forester, 1993) and the use of language 'as an argumentative and persuasive device' (Apthorpe, 1996, p. 20). The discursive dimension encompasses analysis of 'what is said' within and about the process, focusing on content and meaning. Written statements, personal or institutional declarations released in newspaper articles, institutional documents, independent pamphlets and direct interviews carried out by the researcher are all possible sources of information for the analysis.

\section{a) Corpus definition: defining the material for analysis and its sources}

The first step in analyzing the discursive dimension of the policy process is defining the corpus or 'textual universe'. These are the texts by which actors or institutions transmit their ideas about the policy and the process itself in documents, pamphlets, speeches, websites, etc. The discourse corpus requires a coherent organization generally by date and topic. Once the discourse corpus is defined, the next step is to start identifying arguments and claims that contain assertions about the policy process.

\section{b) Identification of claims and narratives within texts, discourses and specific discourse stances}

Claims and narratives refers to the way to 'frame' the policy as a problem by addressing particular events, institutional practices and the narratives about particular policy interventions (Fischer, 2003). By analyzing the claims and narratives used, it is possible to locate their core characteristics and identify discourse coalitions. Hajer (1995) suggests the concept of discourse coalitions to explain how a same discourse can be shared among different actors. He asserts that discourse may bring actors together from different organizations and even ideologies if they identify around a common 
understanding of a policy problem expressed as a unifying storyline, and suggests that discourse coalitions can lead to specific institutional arrangements by influencing the discourses that shape them. His argument is that exclusion and inclusion within policy dynamics are rooted in argumentative tension. As discourse is the expression of knowledge, beliefs and values, by identifying discourse coalitions it is possible to analyze interests and ideas shared among political groups and how they contribute to policy change by transforming discourse and political practices. In the case presented below, the main claim and narratives explored related to stakeholders' representations on 'the environment', in other words the way of portraying human and social relations within the biophysical context and to frame the environmental policy problem addressed by the policy in process to be defined. We reinforce the discourse analysis with Dryzek's (1997) analytical framework in order to explore the environmental narratives of the policy process.

\section{c) Identifying the targeted audiences}

Targeted audiences refer to the 'public' targeted by the discourse. It is important to be aware at this stage that the same stakeholder can elaborate different discourses, speeches or arguments depending on the audience targeted. A comparison of how claims are presented to different audiences is important for addressing further issues of access or exclusion in deliberative practices. Atkinson et al. (2001) recommend paying attention to the style in which reports are written and their claims to truth, authority, closure and representation.

\section{d) Establishing the context of the discourse within the policy process}

Fairclough and other critical discourse analysis authors assert that identifying the context of discourse production and interpretation is central to understanding the policy process itself (Fairclough 1989), (Fairclough, 1992), (Janks, 1997), (Atkinson, Coffey, \& Delamont, 2001). From a sociocybernetics perspective, the sociopolitical conditions of discourse production are part of the context and not part of the system to analyze. However this context helps to identify the limits or borders of the system itself. As external factors, they impact on the shape of the system and explain possible changes in the system related to external influence. For example Carmel (1999), integrates contextual analysis of the institutional framework of political and parliamentary documents when using discourse analysis to explain policy change in Germany before and after unification. Thus while categorizing the corpus material it is important to identify information related to the context and conditions of production as Fairclough (1989) suggests. 


\section{Actors' deliberation within the policy process}

The analysis of deliberative practices is characterized by an interactive approach based on an actor-oriented perspective which focuses on the voices of the individuals and groups involved as well as of those excluded from the decision-making process. This perspective recognizes a degree of agency in the actors, although their interactions may occur within a social and cultural context (Giddens, 1979, 1984) (Bourdieu, 1991) (Long. N. \& Long, A. 1992).

During the policy process, the actors do not intervene in a linear and organized way that can be followed easily. A first step to identifying an actor's perspective is to systematize their motivations, competing values, relationships and interests on the policy deliberation. Principles of stakeholder analysis are generally applied to construct categories of individuals, groups and institutions with a potential interest in or concern about a project or program. The purpose of stakeholder analysis is to provide a better understanding of policy issues and interactions through comparative analysis of the different perspectives and interests. The technique combines elements of institutional appraisal and social analysis in a single analytical framework with the objective of identifying the different agents involved in a plan or project implementation (Overseas Development Agency [ODA], 1995b).

For Grimble and Wellard, stakeholders can be 'any group of people, organized or unorganized, who share a common interest or stake in a particular issue or system and affect or are affected by the decisions and actions in the process' (Grimble and Wellard, 1995, p. 175). We consider that although the principles of stakeholder analysis may help in the identification and systematization of actors at different scales a critical reflection on the stakeholder categorization is needed. For many of its advocates 'principal stakeholders' are those ultimately affected, either positively (e.g. beneficiaries) or negatively (e.g. involuntarily resettled communities) in a policy process, implementation or intervention. For example, secondary stakeholders are generally seen as the intermediaries in the aid delivery process, whereas the key stakeholders are those who can significantly influence or are important to the success of the project (ODA, 1995a: 1). A careful consideration of degree of involvement is needed in a critical view of how an actor or group of actors becomes a stakeholder within a micro-macro continuum (Grimble \& Wellard, 1995). Can a group of actors at the local level be considered primary stakeholders in the policy continuum? Are regional or global NGOs key stakeholders in the local subsystem?

In stakeholder analysis it is important to be clear about the source from which information is obtained. The identification of actors engaged in the policy process can be made through document analysis, a series of semi-structured interviews, and, if possible, participatory observation. Table 2 presents the five observables we chosen to analyze actor intervention, relations and strategies within the policy process: 


\begin{tabular}{|l|l|}
\hline \multicolumn{1}{|c|}{ Observables } & \multicolumn{1}{|c|}{ Descriptor } \\
\hline Positionality of the actor & $\begin{array}{l}\text { Institutional and organizational positionality (e.g. politician of a } \\
\text { specific party, government actor, NGO member, consultant, } \\
\text { active citizen, etc.) }\end{array}$ \\
\hline Type of intervention & Typology of interventions found within the policy process. \\
\hline Momentum of intervention & $\begin{array}{l}\text { We recommend differentiating between sporadic and continuous } \\
\text { intervention }\end{array}$ \\
\hline Relationship to other actors & $\begin{array}{l}\text { Connection or association with other actors that can be } \\
\text { significant in the policy process }\end{array}$ \\
\hline $\begin{array}{l}\text { Strategies to advance claims } \\
\text { in the policy process }\end{array}$ & $\begin{array}{l}\text { Specific actions performed in the policy process to advance } \\
\text { policy claims or influence the policy process }\end{array}$ \\
\hline
\end{tabular}

Table 1: Elements for actor analysis

Although it is not always possible to apply a strictly ethnographic approach (Spradley, 1980), participatory observation of the policy process helps to obtain descriptive qualitative data on particular behaviors, events, groups, institutions or communities. This approach can be very helpful for gaining an understanding of processes where different actors interact such as forums or meetings or by assisting at stakeholder meetings in order to have a chance to grasp the dynamics between actors, exploring the milieus where they perform. It is necessary to acknowledge however, some difficulties in its application to policy process and deliberative settings: for instance, the accessibility or exclusiveness of the policy setting and overlapping activities in different places must be considered. This is why it is important to complement with interviews and document analysis.

\section{Analyzing policy process as a complex system}

A complex system is not something 'given' that exists by itself. Based on Buckley (1993), Luhmann (1992) and Garcia (2006), we consider a complex social system as a relative totality defined by an observer. Its components are heterogeneous and interdefined elements, relations, codes, functions, structures and processes, all operating 
with different degrees of organization. Such components must be analyzed in relation to the other elements and the overall system rather than in an isolated manner.

In the case presented we address, as a relative totality, the Mesoamerican Sustainable Development Initiative (MSDI) of the Puebla Panama Plan (PPP), a regional integration plan for a new 'Mesoamerica' that originally included the seven Central American countries (Belize, Costa Rica, El Salvador, Guatemala, Honduras, Nicaragua and Panama) and the southern states of Mexico. ${ }^{1}$ The PPP aimed to implement a series of infrastructure projects such as roads, ports, airports, communications and energy projects, claiming as their objective 'the promotion of the ecological and human wealth of the Mesoamerican region, within a sustainable framework, respectful of the ethnic, cultural and environmental diversity' (Interamerican Development Bank [IDB], 2002: 5). On June 15th 2001, eight Mesoamerican Initiatives were approved by the PPP decision-making bodies and it was agreed that each of the countries involved would take charge of coordinating one of the agendas and support the implementation of the different projects in its territory.

\section{a) Establishing the limits and system/environment definition within the policy process}

For Brown (1968) and Luhmann (1992) systems are never isolated from their environment; they are intermediated by system boundaries between what lies within and outside the system to be analyzed. In this case study it was important to define the system boundaries, as this was not only a regional policy process impacting on local settings but also a multi-thematic policy agenda. The PPP brought together different development agendas synthesized into eight streams: road connections, commercial links, electrification, telecommunications, human development, prevention and mitigation of disasters, tourism, and sustainable development. The last is the Mesoamerican Sustainable Development Initiative (MSDI).

Although general information on the main PPP process and projects claimed to be public, little information on institutional procedures or the responsible entities and mechanisms was open to public scrutiny. Criticism from NGOs, academic specialists and the media underline the PPP's lack of transparency in the decision making and its unbalanced budget approving favoring infrastructure agendas above the social and human development agenda (Almaguer-Kalixto, 2008).

We chose to the MSDI as object of study as it was an innovative policy attempting to address the environmental dimension of a process of integration between eight countries

\footnotetext{
${ }^{1}$ The South-eastern Mexican states of Campeche, Chiapas, Guerrero, Oaxaca, Puebla, Quintana Roo, Tabasco, Veracruz and Yucatan.
} 
that share a great diversity of natural resources. Most importantly, it was an environmental policy to ensure that all PPP projects incorporate appropriate environmental management and promote the sustainable management of natural resources within a participatory framework (Mesoamerican Sustainable Development Initiative [MSDI], 2003). By choosing to study the MSDI, we start to focus on the MSDI as a system to be analyzed while the PPP, the overall regional plan, was considered part of the context. Figure 2 represents the differentiation between system and context.

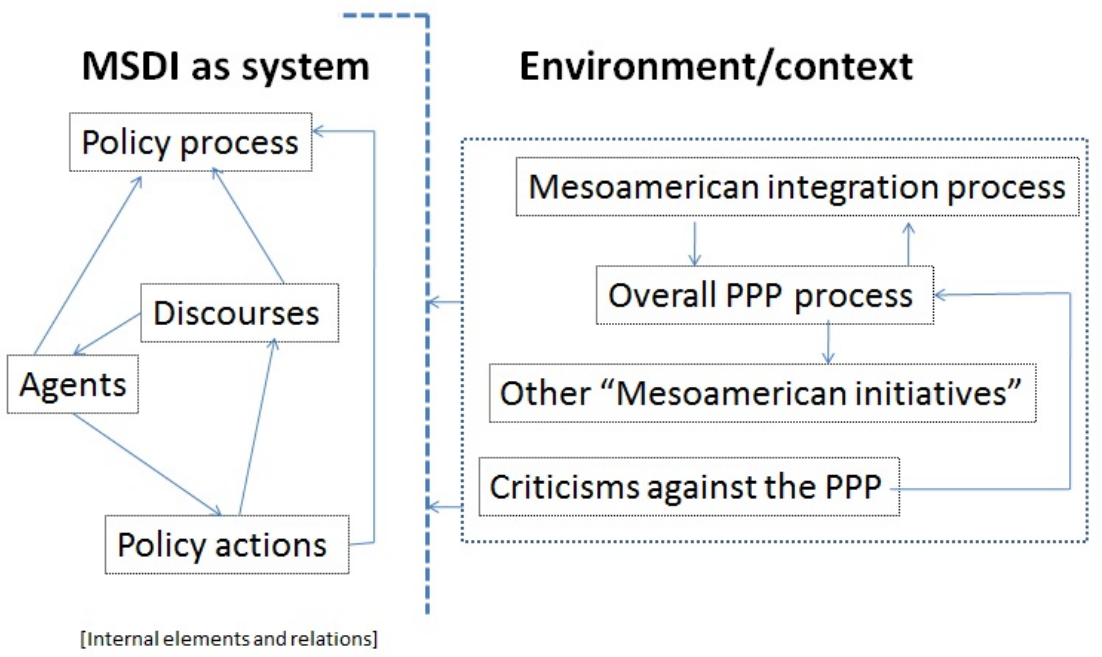

Figure 2. System/environment definition of the case study

\section{b) Identifying the elements within the system: actors, actions and discourse}

Consistent with our proposal to analyze the relationships between policy action, actor interaction and the production of the discourse, a key part of the research was based on obtaining empirical evidence following the methodological steps explained in sections 2 and 3. We undertook two fieldwork trips to identify the stakeholders directly involved and establish links with key informants. As this policy process had a global/regional scale with local implementation, it was necessary to identify where the deliberation process was taking place. Preliminary visits to Mexico in the summers of 2003 and 2004 included a first approach to key actors identify policy makers and members of coalitions resisting PPP implementation. We were also able to test the suitability of the general research questions and identify issues in the debate that were not evident in the literature review or the secondary data collected. A first observation was that although many actors appeared to be engaged within the public sphere expressed in the 
newspapers, only a few were directly involved in the policy design and decision-making process. By identifying the actors directly involved in the process and establishing links with key informants inside the engaged institutions, we were able to participate as observers in different meetings at which deliberation related to the policy process took place.

In the case of individuals and organizations opposed to the PPP we gave priority to those who were active in the claim making (argumentation) against the PPP implementation and had an active stake in the resistance coalition, identified through previous analysis of documents (reports, media, etc.). Once identified, we carried out a first round of interviews. In the case of non-governmental organizations it was preferable to identify those more experienced in the process; those who will make public statements or organize events and meetings. In the case of policy-makers it was more effective to contact individuals in the upper hierarchy or a key individual in the organization. In most cases, references from previous interviewees helped us to gain access to new ones.

We consider Alexiadou (2001) example of semi-structured interview data retrieved when researching the implementation of policy at the level of institutions, and the enactment of such policy by individuals. In our case, interviews were very useful for approaching the reflexivity of individuals in these organizations and finding out their perspectives on how to coordinate their contention regarding the PPP and engage in deliberation with policy makers. Prior to requesting direct information and interviews with the actors, we provided them with information about the research and its objectives. Interviews were directed using a general open questionnaire adapted to the level and sector of the informants, seeking to elicit their specific views of the policy process. When conducting the interviews, the research goal was explained. Anonymity was guaranteed to all interviewees, with only their position and organization disclosed. It was important to make clear to them that information disclosed in a direct interview would not be released to other stakeholders involved in the policy process. Voluntary participation, withdrawal from the research at any point, informed consent, anonymity and confidentiality were some of the ethical clearance aspects involved in this research. In most cases we had an open approach towards the actors engaged, who provided useful information when asked for documents or information to better exemplify their claims and contact details of people who they considered might be useful to the research. Once a set of agents was identified, snowball sampling was applied to identify further potential informants, a request that was repeated at each subsequent interview. Snowball proved to be a useful technique for identifying members of the policy network, gaining access and reporting findings while maintaining confidentiality (Hertz \& Imber, 1995) (Farquharson, 2005).

In the case of the MSDI, the main challenge was finding the person within the institutional structure who was informed of the policy process. This was sometimes 
difficult, due to the constant shifting of personnel, priorities and responsibilities in government institutions as well as in NGOs supposedly engaged in the policy process. We realized that in both policy communities and resistance coalitions, information about the policy process was held by just a few people and not distributed within the structure. Whereas a first round of interviews helped to locate the discussion in the national context and contrast it with the media coverage, a second round of focalized interviews was carried out with key actors from the policy community and the main actors in the coalition against the PPP. The gathering of information through interviews evolved positively as we analyzed and evaluated our own performance to feed back into further encounters.

The integration of actors, perspectives and policy discourse relationships reinforced the analysis of actions where deliberation was taking place. A key event we identified during fieldwork was the fifth meeting of the IDB with civil society groups at the Mesoamerican level in Panama City in February, 2005, which we attended. This was perhaps one of the few deliberative spaces where different perspectives in the international area could meet, as it claimed to be a regional consultation where the environmental framework of the IDB was one of the topics under discussion. Our participation was important in order to be able to approach IDB policy makers and NGOs from the Central American countries previously identified, first because we could meet the people behind the policy documents and see them interacting in a deliberative context, and secondly, because by interacting with the Central American NGOs allowed us to identify other discourses and interests to those expressed by the stakeholders in Mexico, reshaping our perspective of the policy process and the relations between the elements analyzed. Other deliberative arenas were identified within the policy process, some of which we were able to attend. However, thanks to the overall empirical evidence obtained from interviews and documents it was possible to overcome the lack of observation of the deliberative process when it was not possible to engage. The material obtained during the first part of the fieldwork helped to differentiate between the policy process' macro and micro dynamics;' that is, the policy design and definition, and its implementation.

Each project on the PPP agenda provides a potential case study through which to analyse the integration of the MSDI policy design with its implementation in infrastructure projects. We selected a PPP project related to the transport infrastructure agenda: the modernization of Dos Bocas Port in Tabasco (Mexico), identified during the first fieldwork trip, which would enable us to follow the policy process at the domestic level to examine how mechanisms of deliberation and participation functioned locally. A second fieldwork trip focused on retrieving information about the policy process at the local level and learning local views on the implementation of the project and the MSDI as an environmental policy process. Participatory observation in the main communities of the municipality (Paraiso, Comalcalco, El Bellote, Puerto Ceiba) and 
interaction with key local stakeholders helped greatly in understanding the dynamics of the setting, allowing us to access information about the local political dynamics of a project implementation engaging local views on the modernisation of the port as a PPP project. We carried out semi-structured interviews with actors from local organisations, fisheries and municipal authorities, PEMEX managers, government officials, NGO members and members of other Tabasco grassroots organizations.

Most policy process analysis refers to macro or micro levels due to the difficulty of explaining the interrelations between their elements. In order to make sense of the policy process and explain the interrelations between the elements identified within it, our methodological proposal takes the macro, meso and micro levels that have been widely used for the analysis of political issues (Parsons, 1995) (Rhodes, 1997) (Evans \& Davies, 1999) as subsystems within the overall policy system. This enabled the observation of interdependency between elements and the structural relation among such subsystems. Figure 3 shows the main elements of each subsystem and its interrelations, and the following section explains how we integrated the empirical data to explain the policy process at different levels.

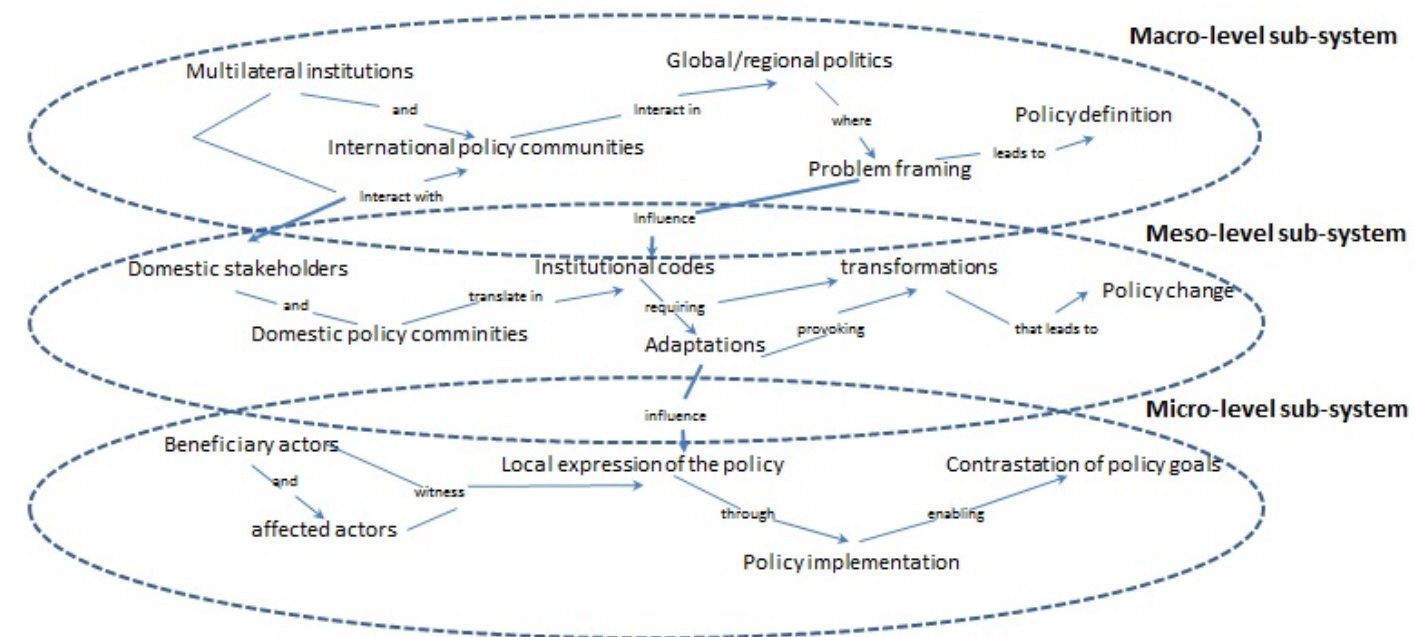

Figure 3: Policy levels as subsystems.

\section{Making sense of the policy process}

From our perspective, policy flows at multilevel settings, particularly when global/regional policy process is to be implemented locally, but where can we say the 
policy is defined, and what is the course of action from one level to another? We consider that an integrated approach is needed to analyze particular courses of action in the process from design to implementation, to explain how some particular actors are included or excluded and why the process changes or takes particular courses of actions.

As the macro-level subsystem, we propose considering the arena of global politics where the interaction of multiple institutions and actors try to influence the initial definition of the policy design. In the case of the PPP, the policy community consisted of Mexican and Central American government officials, officers of multilateral organisations such as the Inter- American Development Bank (IDB); the UN Economic Commission for Latin America (ECLAC); the Central American System for Integration (SICA); the Secretariat for Central American Economic Integration (SG-SIECA), and consultants and other members of the political elite. All of these stakeholders shared a a common objective for stronger liberalisation, regional integration and the attraction of foreign investment, and oriented the policy framing and definition towards a strategy to modernize the region through the PPP.

The PPP was highly contested from its launch in 2001 onwards. Parallel to the PPP policy process, a series of encounters for discussion and resistance were organised by the coalition of Central American, Mexican and American organizations. A significant step in the PPP resistance was the configuration of the Mexican Alliance for the Selfdetermination of Communities (AMAP), and the relationship with other Central American organizations that were against the PPP policy process. Thus the creation of Mesoamerican forums to coordinate a regional movement against the PPP was an important step in bringing information and support against the policy implementation. Mesoamerican forums were held in Tapachula, Mexico (2001), Xelaju, Guatemala (2001), Nicaragua (2002), Honduras (2003) and El Salvador (2004) to consolidate the movement against the PPP. The attention to organisations with an international scope also helped; for example, in 2001, No-PPP Northern Coalition, a network of 20 NGOs from the United States and Canada created to support the Mesoamerican coalition, helped to position the PPP struggle in the media, campaigned to build awareness and distributed information through their particular networks (No-PPP Northern Coalition [No-PPP], 2002).

However the international attention gained by the resistance movement, local grassroots organizations in remote areas had difficulty attending all the encounters due to logistic and economic constraints and had to rely on others' participation to be represented. Some of them heard about the resistance but could not use such coalition to inform about the PPP implementation in its local areas, as in the case of the inhabitants of Paraiso, where the Dos Bocas PPP project was located. The PPP policy community did not acknowledge critical or resistance claims regarding the PPP and its components. No explicit mention of criticism was included in any of its reports during the first 8 years of PPP implementation. Policy documents, digital resources, websites, reviews, 
conferences and press releases are just a few of the many means used to transmit policy goals to a wider public and environmental claims to a wider audience. Regional meetings and signatures of agreement or the release of a new budget are generally events attracting intense public and media attention, with television spots and marketing campaigns to launch them with a positive perspective. In order to reach a wide audience, specific messages are transmitted using television promotional campaigns and printed dossiers. These materials are particularly distributed at meetings with member countries, donors and investors. The media is seen as the arena in which claims are advanced in order to legitimate or criticize the plan. The target audience is general public opinion, but in particular the members of a regional political class, country representatives, the policy elite, donors and investors with an interest in promoting the image of an integrated Mesoamerica. Figure 4 shows the main elements of the macro subsystem and its interrelations.

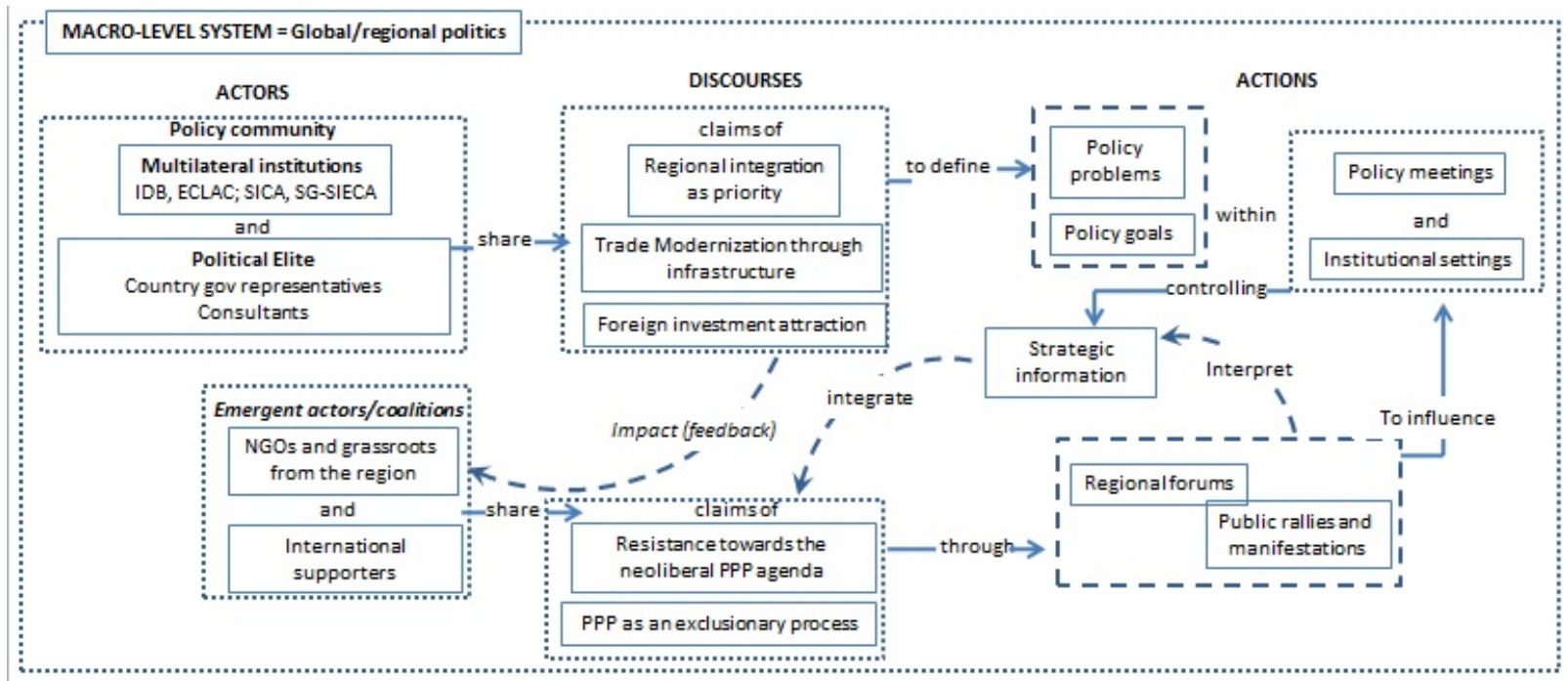

Figure 4: PPP Macro policy level

Whereas the maximum global expression of the policy occurs at the macro level, at the micro level its expression is locally grounded in a municipality or city and is generally related to implementation. The most important feature of the micro-level subsystem is that is where policy commitments can be contrasted with empirical evidence.

The case of Dos Bocas port in Paraiso Municipality, Tabasco drew attention to an area of Mesoamerica known for its plentiful natural resources and their depletion due to unsustainable development practices. In this context, the MSDI would seek to balance 
this situation by implementing a supra-national observance towards sustainable development goals in projects related to the PPP such as Dos Bocas Modernisation port. Findings showed that in general, people of Paraiso did not identify the expansion of the port with the PPP, because although the municipality was hosting a PPP project there was no information about the development of the port beyond what could be accessed on the Internet or learnt from newspapers. We found that at the local level, lack of access to information and the asymmetry between access for privileged and disadvantaged groups was one of the main reasons why local actors did not intervene more actively to contest or deliberate about the implementation process.

Although the macro and micro subsystems help to analyze the differences between policy design and implementation, we still have to explain the procedures that enable policy change or adaptation at the meso-level. Empirical findings helped to define how the meso-level subsystem functioned between the macro and micro as an intermediary via specific codes that would operate as operational closure (Maturana \& Varela, 1999) between the two subsystems. In the meso-level subsystem the policy process design was translated and synthetised by accepted codes of transmission. We found that policy goals are reshaped and integrated into domestic agendas at this level through a series of technical and political decisions discussed in a context of policy deliberation where there are connections and disconnections related to the other levels, based on influence and interests and regulated by the information reaching different actors.

This process involves technical and bureaucratic decisions that can be underestimated if the analytical focus is exclusively oriented to just one end of the policy continuum. As stated by one of the specialists interviewed, this 'is no longer part of the public domain, but part of the technological transfer domain at the level of technical cooperation'.

We found that, actors in the meso-level system exercise political and economic influence under technical claims (i.e. of funding technical assistance, organizational capacity), and through such power they exercise influence in the policy process. Some of the dominant actors at this level were those with the technical capacity to define the process through financial or political support for technical assistance; many of them belonged to the international institutions that shaped the policy at the macro-level subsystem.

Deliberative practices at this level functioned to frame the project, mainly through interaction between members of agencies and government activities. Although the PPP claimed that this deliberative arena is open to all regional and local actors, only economic actors, technical specialist and politicians were able to intervene in such meetings, in contrast with municipal authorities at the local level, who did not see the project and its implementation mechanisms as beneficial to local environmental sustainability. Nor was there a perception of other reinforcements that could benefit the 
integral sustainability of Tabasco. Local actors saw themselves only as spectators forced to adapt their livelihood strategies to the new boom and bust development at this historical moment. Although information about this development is included in public government reports, projections about the project were rarely addressed to local public arenas. Figure 5 shows the main elements of the macro, meso and micro subsystems and its interrelations.

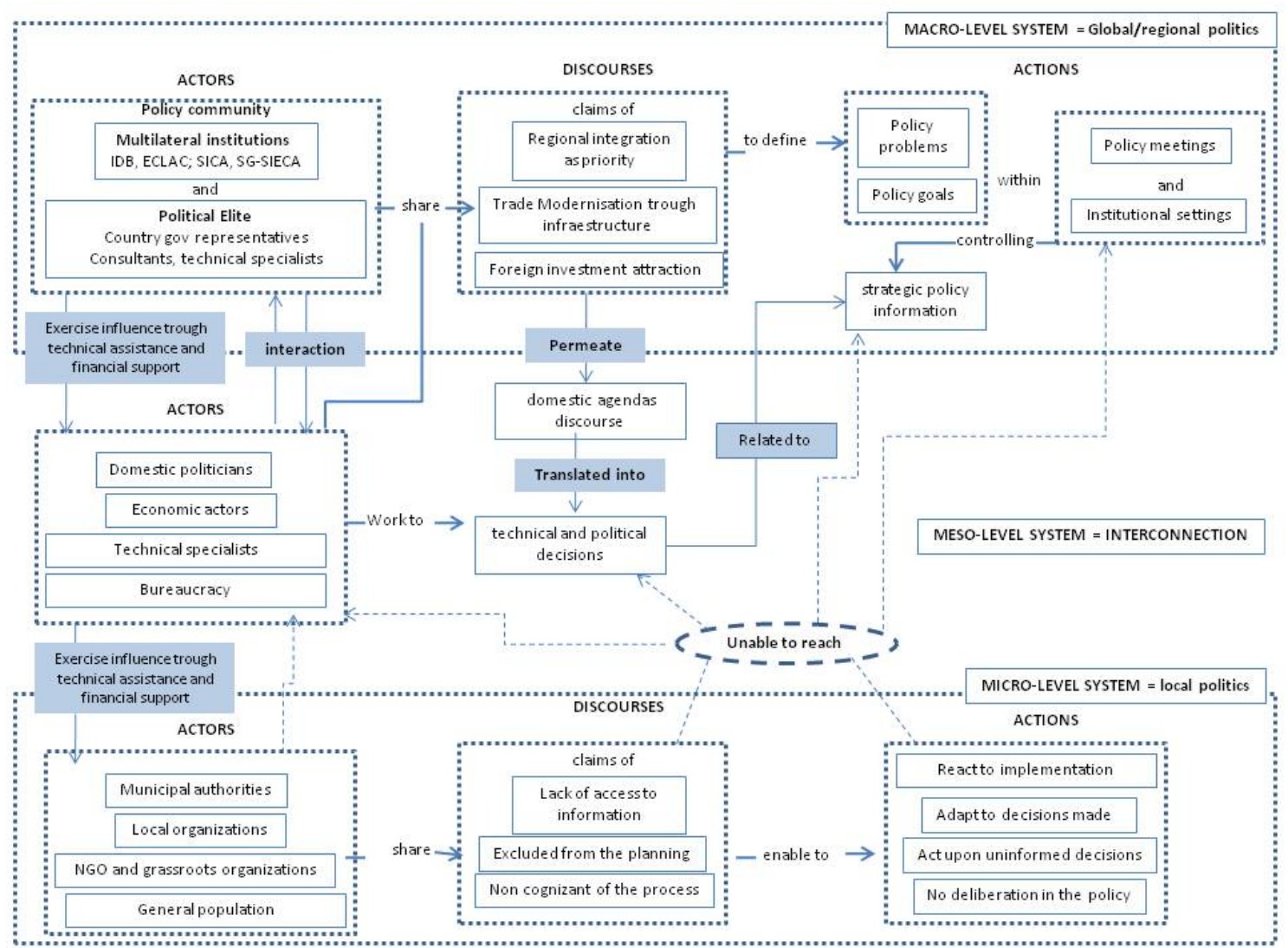

Figure 5: Systemic representation of the three policy levels, focusing on interaction between the actors

Figure 5 is a systemic representation of the policy process with the macro-level subsystem represented at the top and the micro-level subsystem at the bottom. In the case presented, the findings suggest that there is no linkage to the MSDI at the institutional level to connect local project implementation dynamics. That is, at the micro level the MSDI did not have any institutional links with its domestic and local counterparts. The lack of mechanisms to operate at the local level left people potentially 
affected by PPP project implementation unrepresented in the policy debate. Furthermore, without clear institutional mechanisms with which local actors could engage to express their concerns about the process, the PPP enhanced asymmetric access to information and unequal ability to make claims, disagree with and engage in the process, contradicting its objective of promoting ecological and human development for the local communities of Mesoamerica within a sustainable framework.

\section{Conclusions}

This paper seeks to contribute to policy processes that engage global and local levels analyzing the policy process as a complex system. This required taking into account the environmental/contextual conditions of the system under analysis. We argue that attention to the relationship between policy action, actors' interactions and discourse production helped to prove that the processes between macro and micro levels are not linear but inter-defined, and that the feedback loops produce a new or modified input in each level within the process. MSDI of the PPP was used as example because it had heterogeneous elements in its composition of seven countries, several multilateral institutions and other policy actors intervening in the definition of different agendas. We identify bottom-up processes in the emergent resistance movement as a result of feedback loops between policy discourse and emergent actors, but these reactions differed from settings where local communities lack information about the process.

The paper reflects the particular challenges inherent in the logistics of the field work, data collection and systematization at the macro, meso and micro subsystems. Further methodological development is needed to strength the systematization. One possible way of doing this is through the application of computational tools designed ad hoc for the analytical process. This will enable, first, better organization of the gathering of empirical information during the fieldwork, both in gathering secondary data such as policy documents, minutes and media coverage and when producing new empirical information such as interviews and participant observation notes. But also, it will make a second order observation of the policy process, not only by academic researchers but also for practitioners, policy makers and stakeholders, possible. We consider this type of result needs to be at the base of the deliberative process, where participants can strength their argument reflecting and acting upon such information and knowledge. We hope that this paper makes a contribution to the long path to constructing and transiting toward more deliberative democracy. 


\section{References}

Alexiadou, N. 2001. Researching policy implementation: Interview data analysis in institutional contexts. International Journal of Social Research Methodology 4(1): 51-69.

Almaguer-Kalixto, P. 2008. The politics of sustainable development: Analysing exclusion at multiple levels in the environmental policy process. Doctoral dissertation, School of International Development, University of East Anglia.

Amozurrutia, J. A. 2012. Complejidad y sistemas sociales. Un modelo adaptativo para la investigación interdisciplinaria. México: Universidad Nacional Autónoma de México y Centro de Investigaciones Interdisciplinarias en Ciencias y Humanidades.

Andersson, K. \& Kalman, H. 2011. Methodological challenges in the implementation and evaluation of social welfare policies. International Journal of Social Research Methodology 15(1), 69-80.

Apthorpe, R. 1996. Reading Development Policy and Policy Analysis: on Framing, Naming, Numbering and Coding. European Journal of Development Research, 8 (1), 16-35.

Atkinson, P., Coffey, A. \& Delamont, S. 2001. A debate about our canon. Qualitative Research. 1(1) 5-21.

Baber, W. 2004. Ecology and democratic governance: toward a deliberative model of environmental politics. The Social Science Journal. 41 (3): 331-346.

Sutton, R. 1999. The policy process: an overview (Working paper No. 118. London: Overseas Development Institute.

Blaikie, P., and Muldavin, J. 2004. Policy as warrant: environment and development in the Himalayan region. (Working Paper No. 59), Hawaii: East-West Center.

Bordieu P. 1991. Language And Symbolic Power. Cambridge: Polity Press.

Brown G.S.1968. Laws of Form. New York: Dutton.

Cameron, J. \& Ojha, H. 2007. A deliberative ethic for development: a Nepalese journey from Bordieu through Kant to Dewey and Habermas. International Journal of Social Economics 34 (1/2): 66-87.

Devine, F. 1995. Qualitative Methods. In D. Marsh \& G. Stocker (Eds.) Theory and Methods in Political Science, $\left(2^{\text {nd }}\right.$ Ed. London: Macmillan Press.

Dryzek, J. 1987. Rational ecology :environment and political economy, Oxford, UK: Basil Blackwell.

Dryzek, J. S. 1997. The Politics of the Earth: Environmental Discourses. Oxford, UK: Oxford University Press.

Evans M. \& Davies J. 1999. Understanding policy transfer: a multilevel, multi-disciplinary perspective. In: Public administration 77(2): 361-385.

Fairclough, N. 1989. Language and power. London UK: Longman. 
Fairclough, N. 1992. Discourse and Social Change. Cambridge UK: Polity Press.

Farquharson, K. 2005. A Different Kind of Snowball: Identifying Key Policymakers. International Journal of Social Research Methodology 8(4): 345-353.

Fischer, F. 2003. Reframing public Policy. Discursive Politics and Deliberative Practices. Oxford: Oxford University Press.

Fischer, F. 2006. Participatory Governance as Deliberative Empowerment. The Cultural Politics of Discursive Space. American Review of Public Administration, 36 (1): 19-40.

Fisher, F. and Forester, J. 1993. The argumentative turn in policy analysis and planning. Durham, USA: Duke University Press.

García 2006. Sistemas Complejos. España: Gedisa.

Geyer, F. 1995. The Challenge of sociocybernetics. Kybernetes 24, 4. P6-32.

Giddens, A. 1979. Central problems in social theory: action, structure and contradiction in social analysis. London UK: Macmillan.

Giddens, A. 1984. The constitution of society: outline of the theory of structuration. Cambridge UK: Polity.

Grimble, R. and Wellard, K. 1995. Stakeholder methodologies in natural resource management. A review of principles, contexts, experiences and opportunities. Agricultural Systems Journal 55(2): 173-193.

Hajer, M. 1995. The politics of environmental discourse: ecological modernization and the policy process, Oxford UK: Clarendon Press.

Hajer. M. and Wagenaar, H. (Eds.. 2003. Deliberative Policy Analysis: Understanding Governance in the Network Society. Cambridge: Cambridge University Press.

Hertz, R. and Imber, J. (Eds.. 1995. Studying elites using qualitative methods. London: Sage.

Holmes T. and Scoones, I. 2000. Participatory environmental policy process: experiences from North and South. (Working paper 113. Brighton: Institute of Development Studies.

Holmes, T. \& Scoones, I. 2003. Understanding environmental policy processes: cases from Africa. London: Earthscan/James\&James.

Hornung, B.2006. From Cultural relativism to the unity of science by means of epistemological constructivism. foundations for Sociocybernetics. In C. Marcuello \& J. Fandos (Eds.) Sociological Essays for a Global Society. Cultural Change, Social Problemas and Knowledge Society. Zaragoza: Prensas Universitarias de Zaragoza.

Inter-American Development Bank 2002. Hagamos de la integración mesoamericana una realidad: los desafíos de Mesoamérica y el Plan Puebla Panamá, Washington, DC: IDB.

Janks, H. 1997. Critical discourse analysis as a research tool. Discourse: Studies in the Cultural politics of education 18(3): 329-342.

Long, N. and Long, A. 1992. Battlefields of knowledge. The interlocking of theory and practice in social research and development. London UK: Routledge. 
Luhmann, Niklas 1992. Teoría de Sistemas Sociales. México: Anthropos/UIA.

Macpherson, I. Brooker, R. \& Ainsworth, P. 2000. Case study in the contemporary world of research: Using notions of purpose, place, process and product to develop some principles for practice. International Journal of Social Research Methodology 3(1): 49-61.

Maturana, H. y Varela, F. 1999. El Árbol del Conocimiento. Las bases biológicas del conocimiento humano. Madrid: Debate.

Mesoamerican Sustainable Development Initiative [MSDI] 2003. Memorandum of understanding for the coordination of the Mesoamerican Sustainable Development Initiative (MSDI) of the Plan Puebla-Panama. Washington D.C.

Overseas Development Administration [ODA] 1995a. Guidance note on how to do Stakeholder analysis of aid projects and programmes. London: Social Development Department.

Overseas Development Administration [ODA] 1995b. Guidance note on indicators for measuring and assessing primary stakeholder participation. London: Social Development Department.

Parsons, D. 1995. Public policy: an introduction to the theory and practice of policy analysis, Aldershot, UK: Edward Elgar.

Rhodes, R. 1997) Understanding governance: policy networks, governance, reflexivity and accountability. Buckingham UK: Open University Press.

Scott, B. 2003. Cibernética de segundo orden: una introducción histórica. [Second order cybernetics: a historical introduction]. In Marcuello, C. (Ed.), Sociocibernética, lineamientos de un paradigma. Zaragoza: Fernando el Católico.

Spradley J. 1980. Participant Observation. New York: Holt, Rinehart and Winston.

Stake, R. 1995. The art of case study research. California and London: Thousand Oaks and Sage.

Sutton, R. 1999. The policy process: an overview (Working paper No. 118. London: Overseas Development Institute.

Vaus de, D. 2001. Research design in social research. London UK: Sage Publications.

Vigar G. and Healey P. 2002. Developing environmentally respectful policy programmes: five key principles. Journal of Environmental Planning and Management 45 (4): 517 532.

Yin, R. 1993. Applications of case study research, London, UK: Sage.

Yin, R. 2003. Case Study Research: Design and Methods. London UK: Sage. 
Patricia E. Almaguer-Kalixto, José A. Amozurrutia \& Chaime Marcuello Servós

* Acknowledgments: Fieldwork for this article was partially funded by a Fellowship of the Mexican Council of Science and Technology (CONACYT). Thanks to Prof. Kate Brown and Dr. John Cameron who supervise this research at a doctoral stage, and to Prof. Piers Blaikie who's discussion of ideas at the University of East Anglia, inspired the development of key concepts in the making of this article (statements remain responsability of the authors). We also thank all individuals and organisations who provided information, time and personal reflections on the creation of the Puebla Panama Plan's Mesoamerican Sustainable Development Initiative. 